\title{
Homens da província, políticos da nação: a questão provincial no Parlamento, 1829- 1834
}

\author{
Province men, nation politicians: \\ a provincial issue in Parliament, 1829-1834
}

\section{Carlos Eduardo França de Oliveira*}

\section{RESUMO}

Este artigo objetiva examinar o encaminhamento dado pelo Legislativo, em especial pela Câmara dos Deputados, às resoluções provenientes dos Conselhos Gerais, órgãos que constituíram o principal espaço da política provincial em termos de representação dos setores locais e da proposição de projetos exclusivos às províncias entre o Primeiro Reinado e o início da Regência. O fio condutor da análise será a atuação dos deputados mineiros eleitos para as duas primeiras legislaturas (1826-1829 e 1830-1833) diante das propostas ventiladas no período pelo Conselho Geral de Minas Gerais. Com isso se pretende evidenciar uma complexa rede de elementos - aspectos institucionais, concepções distintas de representação, interesses locais, luta política - que pontuaram essa vazão das demandas locais por meio do Parlamento, contribuindo assim para o debate em torno do papel assumido pelos grupos provinciais nos primórdios da construção do Estado nacional brasileiro.

Palavras-chave: Conselhos Gerais. História do Império. Século XIX. Minas Gerais. Parlamento.

\section{ABSTRACT}

This article aims to examine the destination done by the Legislature to the resolutions of the General Councils (particularly the Chamber of Deputies), institution that constituted the main locus of provincial politics in terms of representation of local sectors and proposing unique projects to the provinces

"Doutor em História Social pelo Programa de Pós-Graduação em História Social da Faculdade de Filosofia, Letras e Ciências Humanas da Universidade de São Paulo. 
between first Empire and the beginning of the Regency. The common thread of analysis will be the performance of elected Minas Gerais deputies for the first two terms (1826-1829 and 1830-1833) considering the resolutions during the General Council of Minas Gerais. The goal is to demonstrate a complex web - institutional aspects, different conceptions of representation, local interests, political struggle - that marked local demands on the Parliament, contributing to the debate around the role played by provincial groups in the early construction of the Brazilian empire.

Keywords: General Councils. Brazilian empire. XIXth century. Minas Gerais. Parliament.

\section{Introdução}

Os Conselhos Gerais se firmaram como o principal canal de participação política em nível provincial entre o Primeiro Reinado e o Ato Adicional (1834), que os substituiu pelas Assembleias Legislativas Provinciais. (LEME, 2008). Criados pela Carta de 1824, os Conselhos Gerais deveriam ser instaurados em todas as províncias, exceto naquela em que estivesse sediada a capital do Império. Nas mais populosas (Pará, Maranhão, Ceará, Pernambuco, Bahia, Minas Gerais, São Paulo e Rio Grande do Sul) contariam com vinte e um membros, ao passo que nas demais seriam treze integrantes. Esses seriam eleitos na mesma ocasião e da mesma forma que os deputados e senadores, de modo que a permanência de cada membro no Conselho estaria condicionada à duração de cada legislatura. As sessões dar-se-iam uma vez por ano, com a duração de dois meses, podendo ser prorrogadas por mais um. (BRASIL, 2002).

Os Conselhos Gerais tinham como principal atribuição "propor, discutir e deliberar sobre os negócios mais interessantes de suas províncias; formando projetos peculiares e acomodados às suas localidades e urgências", podendo inclusive receber projetos elaborados pelas Câmaras Municipais. Não estariam incumbidos de deliberar a respeito de propostas que recaíssem sobre a esfera dos "interesses gerais da nação", dos "ajustes de umas com outras províncias", da "execução das leis" e sobre aquelas questões cuja iniciativa deveria partir exclusivamente da Câmara dos Deputados. (BRASIL, 2002).

Suas resoluções seriam remetidas "diretamente ao Poder Executivo, pelo intermédio do presidente da província”. No caso da Assembleia Geral achar-se reunida por essa época, as resoluções ser-lhes-iam enviadas e revertidas como "projetos de lei a obter a aprovação da assembleia por única discussão em cada câmara". Entretanto, nos períodos de recesso do Parlamento, o imperador poderia mandar executar "provisoriamente" as resoluções ou suspender seu juízo sobre a matéria. Tanto as resoluções provisoriamente executadas quanto aquelas temporariamente suspensas pelo imperador teriam como destino a Assembleia Geral após sua reabertura, a fim de serem discutidas. (BRASIL, 2002). 
Incontornável, essa dupla subordinação - à Assembleia Geral e ao Executivo - balizava o alcance político do novo órgão: aos Conselhos Gerais não caberia legislar, mas sim propor matérias que, revertidas em projetos de lei, teriam que necessariamente passar pelo poder decisório dos legisladores e do governo central.

A implantação dos Conselhos Gerais não se deu prontamente, sobretudo por causa da demora no estabelecimento de um regimento específico para eles, aprovado apenas em agosto de 1828. Ademais, sua instalação não se processou uniformemente pelas províncias do Império. No caso da Bahia foi necessária a intervenção do Ministério do Império para que se realizasse a reunião do Conselho. (BRASIL, Assembleia Geral do, 1874-1879, sessão de 06/05/1829). Já Alagoas, Ceará, Espírito Santo e Sergipe tiveram como problema constante o não comparecimento dos membros eleitos. (BRASIL, Câmara dos Deputados, sessão de 18/05/1830). Além da ausência de gratificação e da distância entre o local de residência de parte dos conselheiros e as capitais, houve inicialmente um relativo descrédito para com a natureza política dos Conselhos Gerais, que era eminentemente propositiva, e não legislativa. Havia, ainda, a exigência formal do reconhecimento dos diplomas dos membros do Conselho, que por vezes era morosa e acarretava no atraso do ingresso de alguns integrantes.

Fato de suma importância é o de que muitos dos conselheiros também eram deputados por suas províncias de origem, dado que lança no ar algumas indagações: em virtude da subordinação dos Conselhos Gerais ao Parlamento, haveria um comprometimento, sobretudo dos deputados, com as propostas ventiladas pelos Conselhos Gerais, especialmente por aqueles que ocupavam cargos nas duas instituições? Pode se dizer, por conseguinte, que os deputados eram "homens da província", na acepção de serem seus legítimos representantes? Com efeito, seria então o Parlamento um lócus privilegiado de afirmação dos interesses províncias?

Não obstante a abrangência desses questionamentos, o presente artigo tomará como fio condutor os nexos entre os deputados mineiros das duas primeiras legislaturas - 1826-1829 e 1830-1833 - e as resoluções propostas no mesmo período pelo Conselho Geral de Minas Gerais. A escolha não é casual, já que Minas foi peça-chave na construção do eixo político que deu sustentação à ideia de um governo monárquico-constitucional com sede no Rio de Janeiro. ${ }^{1}$ Além disso, instalado em dezembro de 1828, o Conselho Geral de Minas Gerais foi

\footnotetext{
${ }^{1}$ Estudos recentes têm questionado a tese de que houve um adesismo mais ou menos consensual de Minas Gerais em torno do projeto de poder encabeçado por D. Pedro à época da Independência. Alguns autores apontam para uma solução negociada entre setores provinciais e o círculo de D. Pedro, tendo como pano de fundo uma maior inserção nas redes de poder e negócios proporcionadas por um novo governo sediado no Rio de Janeiro. Nesse sentido, a aproximação com a ideia da construção de um Estado independente passava, necessariamente, pela afirmação de um poder provincial, ainda que os termos de seu funcionamento estivessem por construir. Esse ponto é fundamental para entender como já na gênese do Estado nacional brasileiro houve uma divisão das forças políticas provinciais, que se viram mais ou menos contempladas pela nova máquina pública. Sobre esse ponto ver Bittencourt (2007), Nascimento (2010), Silva (2005) e Silva (2009).
} 
bastante ativo, trabalhando no sentido de estabelecer um movimento contínuo de normatização e aperfeiçoamento da estrutura política provincial, que, num âmbito maior, conjugou-se ao gradativo - e muitas vezes errático - processo de institucionalização do Estado nacional com base numa monarquia constitucional. Por fim, a Minas Gerais constituiu um caso exemplar da existência da figura do "deputado-conselheiro geral". Durante a $1^{\text {a }}$ Sessão do Conselho Geral de Minas Gerais (1828-1829), oito conselheiros mineiros já haviam tomado assento como deputados pela $1^{\text {a }}$ legislatura, levando-se em consideração membros efetivos e suplentes. ${ }^{2}$ Já a $2^{\text {a }}$ Sessão (1830-1833) teve seis membros, entre efetivos e suplentes, eleitos deputados. ${ }^{3}$

\section{Os Conselhos Gerais e o Parlamento}

As primeiras resoluções dos Conselhos Gerais chegaram à Câmara dos Deputados no início de 1829. Entre abril deste ano e maio do seguinte, a Câmara recebeu um número significativo de propostas dos Conselhos de todo Império, realimentando a discussão sobre como elas seriam trabalhadas pelos representantes da nação. (BRASIL, Câmara dos Deputados, 1874-1879, sessões de 09/05/1829; 11/05/1829; 20/06/1829. Na ocasião em que chegaram um conjunto de quinze ofícios oriundos do Conselho Geral de Minas Gerais, o deputado José Carlos Pereira de Almeida Torres, representante daquela província, sugeriu que fosse criada uma comissão para definir que tratamento receberiam tais resoluções. Acabou se decidindo, entretanto, por sugestão de Bernardo Vasconcelos, que elas fossem despachados às diversas comissões da Casa de acordo com seu conteúdo, para depois serem submetidas à discussão no plenário. (BRASIL, Câmara dos Deputados, 1874-1879, sessão de 25/04/1829). Em suma, tratava-se de decidir qual seria o poder de ingerência do Parlamento na manipulação das propostas encaminhadas pelos Conselhos Gerais.

Quando do desdobramento da discussão, retornou à Câmara o projeto por ela organizado sobre as atribuições dos Conselhos Gerais, mas esse só voltaria ao plenário no ano seguinte, no início da $2^{\mathrm{a}}$ legislatura. Algumas emendas foram feitas ao projeto original, dentre elas a suspensão do direito dos Conselhos Gerais exigirem esclarecimentos dos presidentes de província a respeito de suas deliberações, e a proibição de que deputados e senadores desempenhassem, simultaneamente, o cargo de conselheiros. Ainda que alguns deputados tenham se mostrado favoráveis às emendas indicadas pelos senadores, todas elas

\footnotetext{
${ }^{2}$ José Bento Ferreira de Melo, João Joaquim da Silva Guimarães, Custódio José Dias, João José Lopes Mendes Ribeiro, Bernardo Pereira de Vasconcelos, Antonio Augusto Monteiro de Barros, Antonio da Rocha Franco e Cândido José de Araújo Viana.

${ }^{3}$ Elegeram-se conselheiros Bernardo Pereira de Vasconcelos, Batista Caetano de Almeida e José Bento Leite Ferreira de Melo, mais José Custódio Dias e Antônio Pinto Chichorro da Gama como suplentes.
} 
foram rechaçadas pela maioria dos representantes da Câmara. Consequentemente, a incongruência de ideias entre a Câmara dos Deputados e o Senado barrou a aprovação do projeto, de modo que esse não voltou mais à tona. Uma das razões para a não convocação de uma reunião conjunta entre as duas Casas pode ter sido que no ano seguinte, em meio às vicissitudes políticas geradas em torno da abdicação de D. Pedro 1831 e da instalação da Regência, despontou como pauta candente a possibilidade de uma reforma constitucional e, logo, dos governos provinciais. (SLEMIAN, 2006, p.163).

Embora o projeto alternativo elaborado pela Câmara dos Deputados não tenha logrado, é digna de nota a luta desta Casa pela ampliação dos poderes dos Conselhos Gerais. Nesse sentido, uma das discussões mais acirradas ocorridas na Câmara durante a $2^{\text {a }}$ legislatura referiu-se à ingerência que o Legislativo teria sobre as decisões dos Conselhos Gerais. Segundo o artigo 85 da Carta de 1824, os projetos encaminhados à Assembleia Geral pelos Conselhos Gerais deveriam passar por uma discussão antes de serem aprovados ou não. Havia, contudo, uma questão fundamental que a legislação ainda não tocara: teriam os legisladores o direito de fazer emendas às propostas enviadas pelos Conselhos Gerais?

A matéria, discutida no decurso da sessão de 1830, gerou antagonismos entre os deputados. Os defensores de que as propostas não deveriam sofrer emendas pelos parlamentares provinham, sobretudo, das províncias do norte, como o pernambucano Luiz Francisco de Paula Cavalcanti, embora não se possa afirmar que houvesse uma polarização de opiniões de acordo com o local de origem de cada membro da Casa. Em linhas gerais, afirmavam que não caberia à Assembleia Geral intervir nas resoluções dos Conselhos Gerais, pois caso contrário estaria sendo violado o princípio básico desses órgãos, que era o de propor medidas cujos interesses eram especificamente provinciais, e não nacionais. Em contrapartida, nomes importantes das províncias do centro-sul, como os deputados Evaristo da Veiga e Bernardo Pereira de Vasconcelos defendiam a preeminência do Parlamento ante os Conselhos Gerais e, por conseguinte, o direito da feitura de emendas pela Assembleia Geral. Após intenso debate e apertada votação (40 votos contra 32), venceu a indicação de que os projetos aprovados pelos Conselhos Gerais não sofreriam emendas feitas pelos deputados e senadores, sendo passíveis apenas de aprovação ou reprovação. Ficou a cargo dos senadores, ainda, decidir sobre como procederiam sobre a matéria (SLEMIAN, 2006, p. 163170).

Mais do que uma luta em favor dos Conselhos Gerais, a discussão a respeito das emendas lançou luz sobre a própria natureza política desses órgãos. O fato de não estarem juridicamente subordinados ao executivo provincial e de figurarem, grosso modo, como o principal canal de representação política das províncias asseverado pela Carta de 1824, fez com que alguns deputados, como o pernambucano Francisco de Paula Cavalcanti de Albuquerque, encarassem os Conselhos Gerais como "câmaras parciais", uma vez que seus projetos dependiam da aprovação final da Assembleia Geral. (BRASIL, Câmara dos 
Deputados, 1874-1879, sessão de 14/05/1829). Em outras palavras, o que estava em jogo era uma tendência acalentada por alguns parlamentares em atribuir certa dimensão legislativa, ainda que subjacente e indireta, aos Conselhos Gerais. Os próprios deputados passaram a canalizar determinadas demandas para as províncias. Propostas para a criação de vilas, por exemplo, as quais eram costumeiramente encaminhadas à Assembleia pelos presidentes de província, começaram a ser redirecionadas para os Conselhos Gerais (BRASIL, Câmara dos Deputados, 1874-1879, sessões de 10/07/1829 e 16/07/1829).

Aos poucos foi se desenhando na Câmara dos Deputados um modelo de trabalho para as resoluções dos Conselhos Gerais. Na medida em que as diferentes comissões começaram a emitir seus pareceres sobre as propostas recebidas, os deputados da Casa passaram a votálas - aprovando-as ou rejeitando-as, sem a possibilidade de efetuar emendas - consoante com uma seleção prévia feita pelo presidente da Câmara. A aprovação das primeiras propostas e sua consequente conversão em projeto de lei ocorreram somente em fins de 1830, cerca de dois anos após a instauração dos primeiros Conselhos Gerais. Após isso as decisões da Câmara eram encaminhadas ao Senado, a quem competia endossar ou não a posição dos deputados - e posteriormente ao Executivo, para receber a sanção ou veto imperial. A casa vitalícia, cumpre dizer, não ficou alheia às propostas dos Conselhos Gerais. Conforme marcação do seu regimento interno, as matérias que ali chegavam eram encaminhadas, à maneira da Câmara, às diferentes comissões para serem examinadas. (BRASIL, 1831, p. 20-21).

Esse quadro já vinha sendo parcialmente remodelado desde maio de 1830, quando se resolveu, por indicação de Paula Sousa, que fosse nomeada na Câmara dos Deputados uma comissão especial para a análise das representações vindas dos Conselhos Gerais. (BRASIL, Câmara dos Deputados, 1874-1879, sessão de 08/05/1830). ${ }^{4}$ A comissão seria composta por três membros e eleita pelo presidente da Câmara, e seu trabalho dividia-se em duas tarefas principais: fazer uma triagem do material recebido dos Conselhos Gerais e elaborar um parecer recomendando ou não a aprovação de determinada matéria, para aí sim ser impressa e posta para votação em plenário. Já no final de maio de 1830, a comissão então formada por Sebastião do Rego Barros, Bernardo Belizário de Souza e Augusto Xavier de Carvalho apresentou seus primeiros pareceres sobre propostas feitas pelos Conselhos de São Paulo, Minas Gerais, Pernambuco, Paraíba, Rio Grande do Sul e Goiás. (BRASIL, Câmara dos Deputados, 1874-1879, sessões de 24/05/1829 e 28/05/1829). No Senado essa alteração não se processou, permanecendo o sistema da análise pelas comissões já existentes até o Ato Adicional. (BRASIL, Senado do Império, 1914, sessões de 02/07/1831 e 08/05/1832).

No caso de concordância com a proposta, a comissão podia adequar sua redação e a transformar num projeto de lei similar aos que eram elaborados na Câmara. Na maioria dos casos em que uma proposta era recomendada, entretanto, a comissão apenas elaborava um

\footnotetext{
${ }^{4}$ Já em maio os ofícios dos Conselhos Gerais passaram a ser encaminhados diretamente à comissão específica.
} 
parecer, deixando aos demais deputados a tarefa de formatá-lo como projeto de lei. E nem sempre as propostas já saíam da comissão prontas para votação, mesmo quando recebiam um parecer positivo. Era muito comum que o parecer indicasse como melhor alternativa o encaminhamento de certa matéria a uma comissão específica. A comissão também costumava indicar se uma proposta era de interesse "provincial" ou "geral", como ocorreu quando o Conselho Geral de Minas propôs a extinção da Junta de Fazenda daquela província e a instauração de um novo método de arrecadação. Segundo o parecer da comissão, sendo certo de que versava sobre "uma medida geral, que deve ter lugar quando se tratar da reforma da administração de fazenda", a resolução merecia "mui particular atenção" da comissão de fazenda para dar-lhe a devida consideração. (BRASIL, Câmara dos Deputados, 1874-1879, sessão de 16/06/1830). Nem todas as propostas tinham que passar, todavia, pelas comissões ou discussões parlamentares. Conforme os trabalhos dos Conselhos Gerais foram se tornando rotina, aumentaram os casos de resoluções aprovadas sem serem submetidas aos pareceres de comissões ou ao debate em plenário. (BRASIL, Câmara dos Deputados, 18741879, sessões de 28/ 21/07/1832 e 28/07/1832).

Um dos elementos que mais chama a atenção, ao acompanhar o encaminhamento das propostas dos Conselhos Gerais na Câmara dos Deputados, é o de que a maioria deles ficava sem deliberação. Algumas até chegavam a ser debatidas, mas por conta de pedidos de adiamento ou dependência de pareceres de comissão acabavam sem uma apreciação definitiva. Em 1833, o deputado Paula Sousa observou, em tom de descrença, que mais de duzentas propostas aguardavam decisão da Câmara. (BRASIL, Câmara dos Deputados, 18741879, sessões de 03/06/1833). A situação fica ainda mais complexa considerando que, dentre as resoluções que recebiam um posicionamento final da Câmara, não poucas eram rejeitadas pelos deputados. Tomemos o caso de Minas Gerais, cujo Conselho Geral funcionou plenamente de 1828 a 1834. Dentro desse período, o órgão teve sancionadas treze propostas, conforme tabela abaixo: 
Tabela 1. Propostas encaminhadas à Assembleia Geral pelos Conselhos Gerais de Minas Gerais, entre 1828 e 1834, que receberam sanção imperial.

\begin{tabular}{|c|c|}
\hline Propostas & $\begin{array}{l}\text { Mês em que foram } \\
\text { sancionadas }\end{array}$ \\
\hline $\begin{array}{l}\text { Fixa as conhecenças em Minas Gerais em oitenta réis por cada } \\
\text { pessoa de confissão indistintamente. }\end{array}$ & $\begin{array}{l}\text { Aprovada provisoriamente em } \\
\text { março de } 1829 \text {. } \\
\text { Sancionada em dezembro de } \\
1830 .\end{array}$ \\
\hline $\begin{array}{l}\text { Manda cobrar sob fiança os direitos que se arrecadam nos registros } \\
\text { da mesma província. }\end{array}$ & $\begin{array}{l}\text { Aprovada provisoriamente em } \\
\text { março de } 1829 .\end{array}$ \\
\hline $\begin{array}{l}\text { Cria as vilas de S. Manoel da Pomba, Curvelo, Tejuco, Rio Pardo, S. } \\
\text { Romão, S. Domingos do Araxá, Pouso Alegre, Lavras do Funil, } \\
\text { Formigas. }\end{array}$ & Outubro de 1831. \\
\hline $\begin{array}{l}\text { Cria escolas para meninos e meninas em diversas freguesias da } \\
\text { província. }\end{array}$ & Junho de 1831. \\
\hline $\begin{array}{l}\text { Contrata dois engenheiros encarregados de levantar plantas de } \\
\text { todas as estradas e rios navegáveis. }\end{array}$ & Agosto de 1831. \\
\hline $\begin{array}{l}\text { Autoriza os párocos e curas das almas da província de Minas Gerais } \\
\text { a passarem certidões de batismo, casamentos, etc., sem preceder } \\
\text { despacho de autoridade eclesiástica. }\end{array}$ & $\begin{array}{l}\text { Aprovada provisoriamente em } \\
\text { março de } 1832 \text {. } \\
\text { Sancionada em julho de } 1832 \text {. }\end{array}$ \\
\hline $\begin{array}{l}\text { Determina o método que se deve observar no provimento de } \\
\text { cadeiras de primeiras letras. }\end{array}$ & Julho de 1832. \\
\hline $\begin{array}{l}\text { Cria um colégio de educação destinado à instrução da mocidade } \\
\text { indiana de um e outro sexo. }\end{array}$ & Julho de 1832. \\
\hline Eleva diversos curatos ao estatuto de paróquia. & Julho de 1832. \\
\hline $\begin{array}{l}\text { Determina que os juízes de paz façam nos seus distritos o } \\
\text { arrolamento das pessoas existentes, e estabelece providencias } \\
\text { contra vadios. }\end{array}$ & Julho de 1832. \\
\hline $\begin{array}{l}\text { Cria cadeiras de primeiras letras para meninos em diversas } \\
\text { povoações. }\end{array}$ & Agosto de 1832. \\
\hline Cria um curso de Estudos Mineralógicos. & Outubro de 1832. \\
\hline Eleva à categoria de vila a freguesia de Ayuroca. & Agosto de 1834. \\
\hline
\end{tabular}

(Fonte: BRASIL, 1876) 
O número de resoluções que acabaram virando lei é ínfimo quando comparado ao montante de propostas encaminhadas pelos Conselhos Gerais à Assembleia Geral e ao Executivo. O Conselho Geral de Minas encaminhou ao Rio de Janeiro, no segundo ano de funcionamento da $2^{\mathrm{a}}$ Sessão, vinte e nove propostas, mais que o dobro do total das que seriam sancionadas daquele órgão. (O Universal, $\mathbf{n}^{0} 742$, 30/04/1832. A julgar pelas sessões parlamentares e pelas leis aprovadas no período, mesmo destino tiveram as resoluções provenientes dos Conselhos Gerais de outras províncias.

Foram raras as ocasiões em que alguma proposta não tenha sido sancionada pelo Executivo a despeito da aprovação anterior dos representantes da nação (ATAS DO CONSELHO DE ESTADO, 1973-1978, sessão de 06/12/1830). É certo, outrossim, que o Executivo costumava suspender seu juízo sobre algumas matérias que lhe eram dirigidas diretamente pelos Conselhos Gerais sem a aprovação prévia da Assembleia Geral, a fim de obterem sanção provisória ATAS DO CONSELHO DE ESTADO, 1973-1978, sessão de 08/02/1833). Após a Abdicação, aventou-se a possibilidade de que com a Regência, teoricamente mais comprometida com as vozes vindas da província, o Executivo se valesse mais do recurso da aprovação provisória (O Novo Farol Paulistano, $\mathbf{n}^{\circ}$ 35, 03/12/1831; O Universal, $\mathbf{n}^{0}$ 664, 26/10/1831), o que acabou se verificando apenas pontualmente, não alterando significativamente o quadro geral de aprovações. Nada impedia que essas propostas recebessem posterior aprovação da Assembleia Geral. Posto isso, fica evidente que o entrave na concretização das demandas provinciais via Conselhos Gerais estava, sobretudo, na Assembleia Geral, sendo esta a responsável maior pela diminuta aprovação das propostas que recebia.

Excetuando as dificuldades comuns à implantação de qualquer novo órgão, a ausência de uma estreita sintonia entre a Câmara dos Deputados e os Conselhos Gerais ocorreu, em parte, em virtude de certa incongruência de prioridades - talvez mais do que de interesses entre parlamentares e conselheiros provinciais, mesmo porque alguns desses ocupavam, como vimos, ambos os cargos. Além do que, algumas das matérias levadas adiante pelos legisladores revestiam-se de maior envergadura e interesse político se comparados às resoluções emitidas pelos Conselhos Gerais das diversas províncias. Dentre os projetos de lei discutidos na $1^{\text {a }}$ legislatura após a instauração dos Conselhos Gerais, podemos destacar os de dissolução do banco do Brasil, de responsabilização dos empregados públicos e, sobretudo, aqueles que marcavam o orçamento do Império, isso sem mencionar as sucessivas mobilizações de parte dos deputados em torno de questões eminentemente políticas, como as acusações aos ministros da Guerra - Oliveira Álvares - e da Justiça, Lúcio Soares Teixeira de Gouveia. (RIBEIRO; PEREIRA, 2009).

Situação semelhante incidiria na $2^{\mathrm{a}}$ legislatura. Imersos em questões de fundo para a estruturação do Estado - tal como as votações das leis de orçamento e da Regência, a criação da Guarda Nacional, a reforma constitucional, a reestruturação financeira do Império e a 
implantação do novo código de processo criminal (BASILE, 2004) -, os parlamentares parecem ter relegado a um plano secundário a aprovação de medidas oriundas dos Conselhos Gerais como um todo. Mesmo após a Abdicação, quando setores importantes da ala dos chamados liberais "moderados" passaram a ocupar cargos estratégicos no governo, as resoluções advindas dos Conselhos Gerais não ganharam uma atenção sensivelmente maior. Isso ampliaria as pressões, dentro e fora do Parlamento, para que se reformasse a Constituição e transformassem os Conselhos Gerais em Assembleias Legislativas.

Havia certa pressão com vistas a cobrar uma posição efetiva sobre a apreciação das propostas partidas dos Conselhos Gerais. O jornal ouro-pretano Universal publicou em nota seu desagrado com a Câmara dos Deputados, que era vagarosa nos assuntos provinciais, e exortou: "nós lembramos aos nossos deputados que é de sua obrigação promover na Câmara a discussão daquelas propostas do Conselho Geral da província, que são reclamadas pelo voto geral dela". (O Universal, $\left.\mathrm{n}^{\circ} 652,28 / 09 / 1831\right)$. O mesmo Conselho já havia questionado a Câmara sobre que fim de vinte e nove propostas e representações encaminhadas ao Executivo e Legislativo em 1828. Por vezes as pressões surtiam efeito mais concreto. Em 1833, depois de reiteradas solicitações do Conselho Geral da Bahia, a Câmara dos Deputados reuniu-se extraordinariamente, com mais de um mês de antecedência, para discutir o problema do meio circulante naquela província. (BRASIL, Câmara dos Deputados, 1874-1879, sessões de 10/05/1830 e abril de 1833).

A lentidão no direcionamento dos negócios provinciais era inegável, havia ofícios que esperavam anos até receberem algum tipo de tratamento. A fim de evitar demoras desse tipo, o deputado Paula Sousa fez uma indicação, em meados de 1833, para que a comissão dos Conselhos Gerais ficasse encarregada de escolher entre as propostas não decididas aquelas que fossem "mais úteis", tendo como parâmetro a argumentação de "cada um dos Srs. Deputados sobre o estado das suas províncias". Buscava-se com isso vincular o sucesso das propostas dos Conselhos Gerais à atuação das bancadas provinciais, estreitando a ligação dos deputados com as províncias as quais representavam e, ao mesmo tempo, retirando do presidente da Câmara a exclusividade na escolha das resoluções a serem tratadas. Para o deputado paulista "não era possível" que só o presidente detivesse tal poder, ainda mais quando um grande número de propostas aguardava por alguma decisão da Câmara. Ao que tudo indica a recomendação não logrou. De acordo como o representante paulista, o incômodo das províncias poderia ser minorado, também, se o governo executasse provisoriamente as medidas que chegassem às suas mãos. (BRASIL, Câmara dos Deputados, 1874-1879, sessões de 03/06/1833 e 04/06/1833).

Os efeitos desse acúmulo de funções já vinham sendo diagnosticados pelos legisladores desde o início da $2^{\mathrm{a}}$ legislatura. Em 1830, o deputado Batista Caetano de Almeida sugeriu que fossem reservados os sábados e que se priorizassem as propostas oriundas das províncias mais longínquas da capital do Império, como Pará, Maranhão e Ceará. A indicação foi 
rejeitada, porém foi acolhida outra do deputado mineiro Silva Maia para que se prorrogasse uma hora de alguma sessão para as discussões das propostas dos Conselhos Gerais. Pouco tempo depois se aprovou uma requisição de Paula Sousa a qual acrescentava uma hora a cada sessão exclusivamente destinada para tratar das propostas daqueles órgãos. (BRASIL, Câmara dos Deputados, 1874-1879, sessões de 19/07/1830 e 15/09/1830). ${ }^{5}$ Na câmara vitalícia José Martiniano de Alencar tentou aprovar uma medida que conferia aos presidentes e seus conselhos privativos o poder de executar provisoriamente, em casos de urgência, as resoluções dos Conselhos Gerais. A ideia era dar celeridade ao processo de implantação das resoluções e, indiretamente, ampliar a ingerência das províncias na matéria. O senador Caravelas foi radicalmente contra a proposta, alegando que ela encerrava uma atribuição "privativa do poder moderador", não podendo ser entendida a outra esfera de poder. Alencar retrucou-o afirmando que a Carta de 1824 continha um "gérmen federativo" que deveria ser expandido por meio de leis que levassem em conta a ampliação dos poderes provinciais. Não se tratava, segundo ele, de usurpar o poder moderador, mas de munir os presidentes homens do Executivo - de uma atribuição benéfica para as localidades, que "tanto se queixavam de centralização no governo". A proposta recebeu apoio dos senadores Vergueiro, Manoel Caetano e Borges, mas não foi adiante. Travado antes da votação das bases da reforma constitucional, o debate já antecipava pontos de vistas distintos quanto ao papel dos poderes locais na arquitetura política do Império. (BRASIL, Senado do Império, 1914, sessões 15/05/1832, 16/05/1832 e 23/05/1832).

Os motivos que levavam à rejeição de determinada proposta eram vários, a começar pela impossibilidade da Assembleia Geral oferecer emendas aos textos que chegavam das províncias, restrição essa que seria relembrada à exaustão pelos parlamentares até a reforma constitucional. Era comum que deputados opusessem à aprovação de uma proposta por não podê-la emendar. Outras eram repelidas pelo fato de os parlamentares entenderem que de algum modo se estava ferindo a Constituição, ou por serem ineficazes. (BRASIL, Câmara dos Deputados, sessão de 25/09/1830). Havia situações em que eram recusadas ou redirecionadas não por serem inconstitucionais, mas porque esbarravam em outras leis de alcance geral. Se a alegação de inconstitucionalidade se aproximava ao que ocorria a muitos projetos de lei ventilados na Assembleia Geral, o segundo caso era mais complexo, pois implicava na contenção de demandas provinciais e, ao mesmo tempo, no favorecimento de projetos de maior alcance. Esse tipo de desenlace não era consensual e desagrava a muitos parlamentares a depender do contexto. Em meio ao debate sobre uma proposta do Conselho Geral de Minas acusada de conflitar com uma já existente, o deputado mineiro Ferreira de Melo, que havia sido membro daquele órgão na sua $1^{\text {a }}$ Reunião, criticou a argumentação utilizada, ponderando que:

\footnotetext{
${ }^{5}$ No ano seguinte a Câmara retificou sua decisão anterior e deliberou que os sábados fossem reservados para os trabalhos relativos aos Conselhos Gerais. Nova solicitação foi feita por Caetano de Almeida em 1832, quando se decidiu aumentar as sessões dos sábados em uma hora.
} 
Não havia objeto sobre que os conselhos gerais pudessem propor, que não fossem de alguma maneira de encontro a uma lei existente, de maneira que se passasse tal princípio, seria melhor extinguir os conselhos gerais, pois havendo lei que marca o limite de uma vila, por exemplo, não poderia propor a desmembração de parte dela para erigir em outra vila" (BRASIL, Câmara dos Deputados, sessão de 07/07/1832).

A retórica de Ferreira de Melo tinha como objetivo imediato fazer passar a resolução do Conselho Geral mineiro, mas também deixava transparecer um ponto delicado da prática parlamentar referente aos Conselhos Gerais, que era o do equacionamento entre os interesses vindos das províncias com projetos de maior envergadura política. A questão não era nova. Cerca de dois anos antes à fala de Ferreira de Melo, em meio à discussão sobre uma resolução do Conselho Geral do Grão-Pará a respeito dos estrangeiros que domiciliavam naquela província, o deputado Custódio Dias afirmou que, por não poder alterá-la, votava contra, e rematou dizendo que a proposta não poderia passar porque a medida deveria ser geral, e não de uma "única província". (BRASIL, Câmara dos Deputados, sessão de $18 / 09 / 1830)$.

O desfecho da fala do padre mineiro tocava na questão das resoluções encaminhadas pelos Conselhos Gerais serem de caráter "local" - de ingerência das províncias - ou "geral", de competência do Parlamento ou do Executivo. Em julho de 1832, veio à tona na Câmara dos Deputados uma proposta do Conselho Geral de Minas sobre a concessão de terras aos colonos estrangeiros que fossem se estabelecer em solo mineiro. Logo de saída o deputado pelo Rio Grande do Norte, Manuel do Nascimento Castro e Silva, lembrou que havia na Câmara um projeto sobre sesmarias que "devia ser preferido para a discussão, não lhe parecendo justo que a favor da província de Minas Gerais se tomasse uma deliberação que não fosse extensiva às mais províncias". Saíram em defesa da proposta os deputados da bancada mineira Evaristo da Veiga e Batista Caetano de Almeida, este último membro do Conselho mineiro. Ambos alegaram que a proposta respondia às "circunstâncias peculiares" das Minas Gerais, e que uma medida geral não poderia atender todas as províncias a contento, pois cada qual possuía uma demanda específica, argumento que foi apoiado pelo também deputado Ferreira de Melo. Após algumas breves exposições em contrário que sustentavam a necessidade de uma lei geral, a proposta foi por fim aprovada. (BRASIL, Câmara dos Deputados, sessão de 07/07/1832). Na mesma sessão, durante nova discórdia com relação ao caráter "provincial" ou "geral" de outra proposta do Conselho Geral de Minas, Batista Caetano de Almeida lamentou esse tipo de embaraço, declarando que:

A sorte dos conselhos gerais não era das mais favoráveis porque sendo necessário que se reúnam e trabalhem, viam-se obrigados a recomendar depois aos representantes da província que à ponta de 
espada discutissem suas propostas, gastando-se não pouco tempo no combate não só a respeito das de Minas, como das outras províncias, quando os seus verdadeiros órgãos, os Conselhos Gerais, é que lá residem e melhor conhecem os interesses delas. (BRASIL, Câmara dos Deputados, sessão de 07/07/1832).

É evidente que por trás da argumentação de Caetano de Almeida jazia a intenção de legitimar as ações do Conselho Geral de Minas, do qual era integrante, mas o fato era que ela trazia à tona a falta de clareza quanto à atribuição ou não de um "interesse provincial" às resoluções dos Conselhos Gerais e o desgaste político que esse tipo de discussão acarretava. Neste ponto, ao invés de dar vazão aos interesses provinciais, a Câmara acabava represandoos, numa atitude que reiterava a assimetria política entre os dois órgãos e a proeminência do Parlamento no controle desse esboço de prática legislativa provincial que exerceram os Conselhos Gerais. Por mais que essa hierarquia já estivesse dada na Carta de 1824 e no regimento de 1828 , foi somente no decurso da política que ela ganhou contornos mais nítidos.

Barreiras como essas acabaram exigindo por parte dos parlamentares uma ação mais contundente no sentido de levar adiante as propostas dos Conselhos das províncias as quais representavam. O deputado Manoel Odorico Mendes saiu em defesa das resoluções do Conselho Geral do Maranhão, órgão em que atuou como suplente e secretário. O deputado Antonio Fernandes da Silveira, que também era conselheiro geral em Sergipe, foi o principal defensor das propostas feitas pelo Conselho da sua terra natal. Antonio Pereira Ribeiro, suplente na Câmara pela província de S. Pedro do Rio Grande do Sul, sintetizou a atuação de um deputado com relação às propostas vindas do Conselho Geral da província a qual representava. Segundo ele, não cabia a um deputado "sustentar a utilidade da proposta, mas mostrar a sua justiça e necessidade, porque a Câmara não podia estar ao fato de circunstâncias peculiares" de cada província. Em direção semelhante, o mineiro Batista Caetano de Almeida advogou uma ampla aceitação das demandas provinciais: "eu continuo com a minha mania; se é que mania pode chamar-se, de advogar as propostas dos Conselhos Gerais, uma vez que não ferem a Constituição". (BRASIL, Câmara dos Deputados, 1874-1879, sessões de 07/07/1832, 25/09/1830, 13/07/1832, 14/08/1834, 07/07/1832, 14/07/1832). O mesmo argumento foi utilizado no Senado pelo marquês de Barbacena. (BRASIL, Senado do Império, 1914, sessão de 24/05/1832).

O negociante Batista Caetano de Almeida, vale dizer, foi um dos principais articuladores da bancada mineira em prol das resoluções do Conselho Geral de Minas durante a $2^{\circ}$ legislatura. Mineiro natural de Camanducaia, logo cedo se enraizou em São João del-Rei, onde estudou e iniciou-se no ramo dos negócios. Firmou algumas sociedades comerciais, dentre elas a Lisboa \& Almeida, casa comissionaria de produtos do interior localizada no Rio de Janeiro. Caetano de Almeida foi vereador, juiz de paz, membro da Mesa Administrativa da 
Santa Casa da Misericórdia, suplente do Conselho da Presidência e membro efetivo do Conselho Geral de Minas Gerais. Em 1827, levou a público o primeiro periódico de São João del-Rei, o Astro de Minas, de oposição ao governo pedrino. (MOTTA, 2000).

O fato de Caetano de Almeida ter negócios em Minas Gerais e ser membro do Conselho mineiro investiu-o de um maior conhecimento de causa a respeito das propostas daquele órgão, o que em termos práticos auxiliou-o no convencimento dos demais parlamentares. Quando do debate sobre uma proposta do Conselho Geral de Minas acerca da convocação de companhias para empreenderem a navegação de rios e a abertura de estradas - projeto esse que fora expendido meses antes, em Ouro Preto, pelo próprio Caetano de Almeida - este apelou para uma argumentação marcadamente técnica para expor os benefícios aos outros membros da Casa, o que resultou na aprovação da matéria. (BRASIL, Câmara dos Deputados, sessão de 07/07/1832).

O Conselho de Minas teve em Bernardo Pereira de Vasconcelos outro importante ponto de comunicação com a Câmara dos Deputados, de forma que a atuação do político naquela Casa, sobretudo durante o final da $1^{\text {a }}$ legislatura (1826-1829), foi pautada por sucessivas tentativas em aprovar as resoluções emanadas do órgão mineiro. Em 14 de abril de 1829, Vasconcelos requereu que se solicitasse a aprovação pelo Governo da proposta do órgão mineiro sobre o problema do cobre falso em circulação, pedido que foi refeito dias depois, com aprovação da Câmara. Em maio do mesmo ano, após a comissão de constituição expor seu parecer sobre uma proposta do Conselho Geral de Minas sobre as conhecenças, Vasconcelos pediu, com aprovação dos demais colegas, que a mesma fosse impressa junto com o parecer a fim de agilizar a matéria. Um método utilizado por Vasconcelos era o de tentar inserir a apreciação de alguma matéria do Conselho mineiro cujo teor fosse análogo ao que tramitava no plenário. Em meio à discussão de um parecer da comissão de justiça civil sobre uma representação do vice-presidente da província de São Paulo que pedia a criação de uma casa de correção naquela província, o deputado ponderou que a mesma comissão analisasse proposta similar do Conselho Geral de Minas. Dias depois a comissão formada pelos deputados João Ricardo da Costa Dormund e Antonio Augusto da Silva expôs seu parecer negativo com relação à proposta do Conselho mineiro, por julgá-la "exorbitante das atribuições" daquele órgão. A comissão alegou que a matéria, aparentemente particular, era de interesse geral, e por isso deveria ser tratada pelos deputados como um projeto de aplicação geral. Vasconcelos se opôs ao parecer, afirmando que a matéria tinha explícito interesse provincial. Tentou mandar imprimir a matéria em caráter de urgência, porém fracassou. (BRASIL, Câmara dos Deputados, sessões de 14/04/1829, 24/04/1829, 11/07/1829, 06/07/1829 e 29/07/1829).

Era comum que a espera por um parecer de comissão retardasse a discussão de alguma resolução. Os deputados sabiam que ao passar pelo crivo negativo de determinada comissão uma proposta feita pelos Conselhos Gerais perdia sua força, aumentando a chance de ser 
refutada pelos demais parlamentares. Por isso mesmo Vasconcelos requereu, com sucesso, que uma proposta do Conselho Geral mineiro sobre a circulação de cobre falso fosse impressa e discutida independentemente do parecer da comissão de impostos e rendas públicas. (BRASIL, Câmara dos Deputados, sessão de 29/08/1829). É provável, ainda, que Vasconcelos tenha utilizado sua influência para atuar a favor do Conselho Geral mineiro nas ocasiões em que compôs alguma comissão parlamentar. Em junho de 1830, por exemplo, quando foi integrante da comissão da fazenda, esta emitiu um parecer favorável a uma representação do Conselho Geral mineiro sobre a cobrança de emolumentos que era feita no registro de Paraibuna a título de termo. (BRASIL, Câmara dos Deputados, sessão de 21/06/1830). ${ }^{6}$ A relação contínua entre Conselhos Gerais e Parlamento fez com Bernardo Pereira de Vasconcelos sugerisse, em sessão do Conselho de Minas, que este solicitasse às duas Casas legislativas os diários e atas dos seus trabalhos. (ATAS DO CONSELHO GERAL DE MINAS GERAIS, 1831, sessão de 14/02/1831).

No Senado, o engajamento com as propostas dos Conselhos Gerais se fez em escala menor, muito embora a análise de resoluções constituísse atividade quase diária dos senadores, o que em certa medida contradiz os ataques da oposição de que a casa vitalícia dava as costas para a política provincial. O envolvimento pessoal em menor escala tem explicação. Antes da chegada de homens como Paula Sousa, Ferreira de Melo e Feijó, praticamente nenhum senador havia sido conselheiro geral, até porque muitos dos senadores residiam na Corte. A falta de conhecimento de causa das peculiaridades provinciais também pesava, mas o fato principal era que os senadores se arvoravam da condição, mais do que os deputados se pensarmos em termos de conjunto, de representantes da nação, não das províncias. A vitaliciedade do cargo lhes abonava maior liberdade de ação e, respectivamente, maior independência para com as bases eleitorais, de modo que as pautas provinciais se prestaram menos ao uso político do que na Câmara dos Deputados. Ali se fortaleceu cada vez mais a ideia de que uma resolução deveria ser barrada apenas se ferisse a Constituição, ao passo que no Senado o rigor foi maior. Vale lembrar, ainda, que a nomeação da primeira bancada senatorial (1826) tencionara implantar no Legislativo uma base de apoio ao governo pedrino - convertida majoritariamente em oposição durante o período regencial -, o que provavelmente diminuiu o empenho dos senadores com relação às propostas dos Conselhos Gerais, que por sinal eram compostos, em grande medida, por setores provinciais contrários ao imperador e, posteriormente, adeptos da Regência.

A câmara alta brecou resoluções dos Conselhos Gerais aprovadas pelos deputados, embora nos pareça exagerado creditar aos senadores o baixo índice de propostas convertidas em lei. ${ }^{7}$ Evitou-se, também, decidir sobre resoluções consideradas de atribuição

\footnotetext{
${ }^{6}$ Os demais integrantes da comissão de fazenda eram João Mendes Viana, Duarte da Silva, Gervásio Pires Ferreira e Bernardo Belisário Soares de Sousa.

${ }^{7}$ Em julho de 1832, o Senado barrou uma proposta do Conselho Geral de Minas Gerais que visava à criação de uma cadeira de taquigrafia. A proposta havia sido aprovada dias antes, sem discussão, pela Câmara dos Deputados. (BRASIL, Senado do Império, 1914, sessão de 16/07/1832.
} 
exclusiva da Câmara dos Deputados, como a criação de impostos. Minas Gerais não teve um membro no Senado que defendesse explicitamente seu Conselho Geral. Vergueiro, eleito senador por Minas Gerais, mas ligado à política paulista, mostrou envolvimento com questões de política local, porém sem a contumácia dos tempos de deputado. (BRASIL, Senado do Império, 1914, sessões de 27/06/1831e 16/07/1832).

A subordinação obrigatória dos Conselhos Gerais à Assembleia Geral, bem como a ausência de um entendimento sobre a natureza das propostas emitidas por esses órgãos demandaram, como é possível notar a partir dos exemplos supracitados, certo empenho por parte dos legisladores no sentido destes verem aprovadas as demandas provinciais com as quais concordavam. E a equação para tal não era simples: era preciso apontar para a importância da proposta em questão, defendê-la em termos legais e, sobretudo, persuadir grupos de outras províncias da necessidade de sua aprovação, aspectos que na ótica d'o Universal fizeram dos Conselhos Gerais órgãos de pouca concretude prática:

Nas assembleias gerais as causas de uma província dependem dos deputados de outra. E que interesse pode tomar nelas um homem estranho sem um pleno conhecimento das necessidades peculiares da província que não o elegeu, e talvez mesmo se afeto a ela? E como darlhes o devido valor? Se mesmo entre os representantes de uma só vemos tantas discordâncias, quantas haverão entre os de muitas? Que será pois daquela província que não tendo senão um Deputado não achar quem apoie os esforços que ele fizer bem dela? ( $O$ Universal, $\mathbf{n}^{\circ}$ 1087, 03/10/1834).

Para o Novo Argos, o problema ia além da falta de conhecimento das peculiaridades provinciais pelos deputados. Ele residia, antes, no conflito de interesses entre as províncias. Os interesses de Minas Gerais, por exemplo, difeririam daqueles das províncias litorâneas:

Sendo diversos nossos interesses dos das províncias marítimas, e pertencendo a estas províncias a maioria dos representantes da nação, poucas das propostas do Conselho Geral obterão a aprovação da Assembleia Geral pela falta de conhecimentos peculiares de Minas, conhecimentos que só se podem encontrar no seio do Conselho, ocupado todo com as representações das Câmaras, e dos povos. (O Novo Argos, $\mathbf{n}^{\circ}$ 68, 01/03/1831). 
Alguns casos permitem elucidar a pluralidade de implicações que circundava a aprovação de determinada proposta, a começar por um ocorrido em 1832, durante a discussão sobre uma resolução do Conselho Geral de São Pedro do Rio Grande do Sul, que tinha como finalidade construir um chafariz na cidade de Porto Alegre. Já no início da discussão, o deputado suplente pela Bahia Francisco Jê Acaiaba de Montezuma afirmou que só votaria pela resolução "se a câmara se engajasse a dar a quantia necessária para se construir um chafariz na cidade da Bahia, porque era na verdade escandaloso que em uma tão rica província, e tão produtiva, os seus habitantes se vissem obrigados a mandar buscar água numa légua fora da cidade”. O deputado pelo Rio Grande Salvador José Maciel redarguiu observando que o fato de o Conselho Geral da Bahia não ter feito proposta semelhante não era "razão suficiente para se deixar de aprovar a proposta do Rio Grande do Sul, cujos habitantes, por falta de aqueduto estavam sujeitos a doenças provenientes da insalubridade da água". A resposta do deputado baiano foi a de que "talvez os conselheiros da Bahia não o fizessem por causa da falta de recursos". (BRASIL, Câmara dos Deputados, sessão de 14/07/1832).

Um tanto inusitada, a última fala de Montezuma tocava num aspecto fundamental que era o da origem dos recursos que seriam despendidos para por em execução as resoluções dos Conselhos Gerais, uma vez que estes não dispunham de nenhum suporte legal que lhes assegurasse uma renda fixa para o cumprimento de suas resoluções. Por conta disso, ainda sob o governo de D. Pedro, o ministério do Império fez circular uma decisão alegando que não cabia ao Governo disponibilizar recursos para a implantação das resoluções dos Conselhos Gerais, e que portanto o dinheiro deveria ser extraído das próprias Juntas da Fazenda Provinciais (depois Tesourarias Provinciais), tendo como base o montante destinado a cada província pelas leis do orçamento de cada ano financeiro. (COLEÇÃO DAS DECISÕES DO GOVERNO DE 1830, 1876, Decisão do Ministério do Império de 23 de novembro de 1830).

Os deputados Duarte da Silva e Soares da Rocha, por sua vez, votaram contra a proposta porque a acharam "muito pequena" para ir à Assembleia, e sugeriram que ela fosse concretizada pelo próprio governo provincial, utilizando os recursos estipulados na lei do orçamento para obras públicas daquela localidade. Para Honório Hermeto, também contrário à resolução, se a proposta passasse poderia entender-se que a despesa com o chafariz não estava vinculada ao dinheiro consignado no orçamento para obras públicas, gerando déficit aos cofres provinciais. Caetano de Almeida concordou com a pouca monta da proposta, mas avaliou que uma vez feita, não custava aprová-la, cabendo ao Conselho da Presidência o direcionamento dos recursos para a feitura da obra. A resolução acabou aceita, embora propostas semelhantes não obtivessem êxito igual. (BRASIL, Câmara dos Deputados, sessões de 14/07/1832 e 28/07/1832). 
Pela mesma época veio à baila a discussão de uma proposta do Conselho Geral de Minas, já mencionada anteriormente, sobre o estabelecimento de um local de criação de animais naquela província. A proposta não tinha nada de excepcional se não fosse o detalhe de que o local escolhido para o empreendimento era o terreno da Fazenda Nacional da Cachoeira, que supostamente havia sido de domínio do ex-imperador. (ATAS DO CONSELHO GERAL DE MINAS GERAIS, sessão de 14/12/1831). Quando entrou em discussão na Câmara, foi pugnada por Batista Caetano de Almeida, para quem a "utilidade da proposta" era evidente, podendo inclusive servir de exemplo para outras províncias. O deputado mineiro foi contestado por José Bonifácio, então deputado suplente pela Bahia e tutor do filho do ex-monarca, que afirmou ser a fazenda propriedade particular - bem herdado pelos descendentes de D. Pedro - e por isso mesmo o Conselho Geral não poderia dela dispor, no que foi apoiado por Rebouças. Então entrou em cena Honório Hermeto, que, munido de uma argumentação repleta de pormenores, procurou mostrar a legalidade da matéria, observando que não se tratava de um bem da família real. Embora reconhecesse que, por conta da vacância do trono e da tutoria do filho de D. Pedro, a Assembleia Geral passara em certa medida a fazer a "guarda dos bens da nação", o deputado pela Bahia Miguel Calmon Du Pin achou prudente que a matéria fosse adiante até o envio de documentos que pusessem às claras o assunto.

O debate assumiu contornos marcadamente políticos, repercutindo até na imprensa $(O$ Novo Argos, $\mathbf{n}^{\circ}$ 136, 26/06/1832). Ferreira de Melo votou pelo adiamento da proposta, por não querer que o Conselho de Minas ficasse suspeito de obrar "com leveza e sem reflexão" ou de querer "tirar uma propriedade pertencente ao imperador". No mesmo sentido opinou o também mineiro Custódio Dias, para quem "se queria dar grande expansão ao negócio" referindo-se aí aos detratores da proposta. Percebe-se, na fala dos deputados mineiros, certo receio de que a aprovação da proposta fosse utilizada politicamente contra o Conselho de Minas e aqueles que a endossassem, colocando-os contra o Executivo e, no limite, contra o Estado. Venceu o adiamento da proposta, que não voltou mais à tona. Novos enfretamentos ocorreriam em sessões subsequentes. (BRASIL, Câmara dos Deputados, sessões de 02/06/1832 e 21/07/1832).

Em torno de debates como esses gravitavam objetivos que iam além de uma postura localista e ciosa em satisfazer as demandas provinciais. Em ambos os casos impunha-se aos anseios locais a subordinação a um patamar de negociação interprovincial mais amplo, manifesto dentro do Legislativo, num intricado jogo de troca de interesses. Comportamentos como os de Montezuma e Ferreira de Melo expunham o fato de que os assuntos provinciais não eram um compartimento isolado e que, portanto, não estavam alheios às conjunturas da política imperial. Não nos esqueçamos que Montezuma se firmou como um dos principais nomes da oposição aos "moderados" dentro da Câmara após a Abdicação, ao passo que na época do adiamento da proposta do Conselho Geral de Minas sobre a fazenda de criação encetava-se um forte movimento que alardeava pela destituição de Bonifácio da tutoria do futuro D. Pedro II. Neste sentido, o manejo das propostas dos 
Conselhos Gerais serviu para os parlamentares como instrumento de luta e negociação política, em que o objetivo último nem sempre foi o de afiançar os interesses provinciais. Este tipo de postura foi detectado pelo redator d' $O$ Universal, em 1833, num período que os "moderados", embora ocupando cargos de destaque no Executivo, sofriam cerrada oposição na Câmara. Adepto da Regência e defensor da ala "moderada" da Câmara, o jornal condenou o uso político de uma proposta do Conselho Geral mineiro pela então oposição:

\begin{abstract}
Uma comissão da Câmara dos Deputados julga atendível a proposta, converte-a em projeto de lei, e entra logo em discussão. Os membros da oposição fazem-lhe a mais viva guerra, e sob o pretexto de que esta medida era uma arma terrível nas mãos do Governo, opõe-se a que o projeto seja adotado; mas a maioria da Câmara que felizmente não se compõe de homens exagerados nos seus princípios políticos, tem defendido com calor a proposta (...) Foi assim que aconteceu propondo o nosso Conselho Geral na Sessão do ano passado uma semelhante medida a favor do $1^{\circ}$ corpo de cavalaria de $1^{\text {a }}$ linha destacado nessa província. (O Universal, $\mathrm{n}^{\circ} 896,01 / 07 / 1833$ ).
\end{abstract}

Não é ocioso notar, todavia, que o engajamento das bancadas provinciais na aprovação de propostas dos Conselhos Gerais referentes à província a qual representavam constituía uma tendência geral, mas não uma regra, o que nos faz remeter à ideia da relativa independência dos deputados para com seus eleitores dentro dos regimes representativos. Nas primeiras décadas do século XIX vicejava a concepção de que um parlamentar não representava necessariamente quem o elegia, mas o conjunto de cidadãos que compunha a nação. (PITKIN, 1967). Na Inglaterra do século XVIII e na França revolucionária ganhou aceitação a ideia de que os membros do parlamento representavam a nação em seu conjunto, ao invés de interesses particulares. (MANIN, 2008). Entre os parlamentares brasileiros eram frequentes as falas nesse sentido, porém enunciados dessa natureza, por mais convincentes que pareciam ser, na realidade se prestavam a usos políticos imediatos e, mais do que isso, encobriam um ponto fundador dos regimes representativos modernos: a existência de um grau de independência dos representantes com relação aos representados. É certo que a garantia de eleições periódicas priva, na prática, os representantes de uma total independência dos representados. As eleições e, sobretudo, as reeleições, marcam um momento em que o representado avalia o representante para qual cedera sua parcela de soberania e se vê na possibilidade de ratificar ou não sua escolha. A despeito disso, o fato é que em nenhum regime representativo surgido desde fins do século XVIII estabeleceu-se algum mecanismo para os representantes agirem em conformidade com as instruções dos representados. 
Mesmo entre grupos mais ou menos afinados politicamente havia discordâncias, à semelhança do que ocorria nos projetos elaborados pela Câmara dos Deputados. Em julho de 1832, iniciou-se a discussão sobre uma proposta do Conselho Geral mineiro que extinguia a Junta da Administração Diamantina de Tejuco. Evaristo da Veiga, deputado por Minas que dependia das articulações de grupos do sul de Minas para se eleger por aquela província, rechaçou a proposta "porque lhe parecia que tratava de objeto que não estava nas atribuições do conselho, por ser negócio de interesse geral, além de que ia de encontro a uma lei”. $O$ posicionamento de Evaristo conflitava com seus companheiros de bancada Honório Hermeto, Caetano de Almeida e Ferreira de Melo, que defenderam a aprovação da proposta. Uma semana depois foi a vez do deputado sergipano Fernandes da Silveira votar contra uma resolução do Conselho Geral do Sergipe sobre a criação de práticos para as barras daquela província. (BRASIL, Câmara dos Deputados, sessões de 07/07/1832 e 14/07/1832).

É preciso atentar, ainda, para o fato de que as demandas provinciais não chegavam ao Rio de Janeiro apenas via Conselhos Gerais, mas também a partir da própria iniciativa dos deputados, que nessas situações se projetavam mais como representantes da província - ou de pelo menos parte dela - do que da nação. O deputado Ferreira de Melo propôs uma série de medidas voltadas para o desenvolvimento das Minas Gerais, dentre elas a criação de um correio entre Minas e São Paulo e a reformulação dos termos de cobrança do dízimo do café para as duas províncias, bem como outra que previa a diminuição dos encargos referente ao transporte de mercadorias dentro do solo mineiro. (BRASIL, Câmara dos Deputados, sessões de 09/05/1828 e 28/07/1828). Não por acaso, todavia, propostas como essas, ventiladas também por deputados de outras províncias, incidiram com maior frequência antes da instauração efetiva dos Conselhos Gerais, o que reitera a tese de que, a despeito das suas limitações, os Conselhos Gerais constituíram-se como o principal espaço de formulação de políticas públicas em nível provincial. Veja-se o caso da supracitada proposta de alteração do dízimo do café, que uniu deputados paulistas e mineiros contra o parecer feito sobre a matéria pela comissão da fazenda da Câmara. Esta claramente privilegiou os cofres do Rio de Janeiro, propondo que o dízimo fosse arrecadado na Corte e não nas províncias, onde ocorria um "roubo escandaloso" protagonizado pelos "arrematantes paulistas e mineiros", segundo palavras do deputado Sousa França. A matéria acabou sendo adiada e Vasconcelos, que se colocou ao lado dos seus conterrâneos, observou que competia ao Conselho Geral de Minas "examinar as circunstancias particulares e propor o método de arrecadação mais conveniente”. (BRASIL, Câmara dos Deputados, sessão de 28/07/1828). 


\section{Considerações Finais}

Em meio à discussão e aprovação do Ato Adicional, no curso de 1834, a Câmara dos Deputados e o Senado praticamente suspenderam os trabalhos relacionados aos Conselhos Gerais e a outros negócios provinciais. Os deputados votaram que as resoluções dos Conselhos seriam enviadas para uma comissão que as repassaria para as províncias assim que as Assembleias Legislativas fossem instaladas. Findava-se um período de quase seis anos em que o Legislativo teve a importante incumbência de dar vazão às demandas provinciais consubstanciadas nos Conselhos Gerais de todo o Império.

Pôde se notar que o problema em torno dos Conselhos Gerais não estava, ao contrário do que ainda faz crer parte da bibliografia, ${ }^{8}$ tão somente na sua limitação políticoadministrativa, cujo lado mais evidente era a falta de competência legislativa. Se a questão fosse apenas essa, poderia ter sido parcialmente remediada pelos próprios legisladores, sobretudo pelos deputados, se estes tivessem adotado um expediente mais sistemático de aprovação de propostas, como chegaram a sugerir políticos mais coniventes com os Conselhos. Mas não, o que se deu foi um encadeamento de relações entre eleitores, conselheiros gerais, deputados (muitos deles também conselheiros) e senadores que, em função de fatores como disputas políticas, heterogeneidade das bancadas provinciais, relativa independência dos legisladores diante das bases eleitorais e existência de assuntos de maior relevância nacional a serem tratados no Parlamento, praticamente inviabilizou a etapa final do sistema de funcionamento dos Conselhos Gerais, qual seja, a aprovação de suas propostas pela Assembleia Geral.

Para os contemporâneos a conclusão óbvia era que os Conselhos Gerais precisavam de atribuições mais substantivas, constatação que tomou vulto a ponto de se tornar o estandarte maior dos que brandiriam pela da reforma da Constituição a partir da reta final do Primeiro Reinado. Tema fulcral, sem dúvida, mas que tende a eclipsar outras questões igualmente importantes. A começar pela concepção de representação, que tal como disposta na Carta de 1824 possibilitava apropriações e usos variados conforme a ocasião, sintoma de como $o$ ato de representar era uma prática em construção permanente e que misturava a experiência política anterior à fundação do Império do Brasil - especialmente das Câmaras Municipais, das Cortes de Lisboa e das Juntas de Governo - com a necessidade imediata de se impor uma agenda nacional que se sobrepusesse às aspirações de cunho mais regional.

\footnotetext{
${ }^{8}$ É comum entre trabalhos de síntese e aqueles que adotam cronologia mais ampla para analisar a história política e institucional do Império que se tome a falta de ingerência legislativa dos Conselhos Gerais como o motivo maior, senão o único, que levou à criação das Assembleias Legislativas Provinciais. Essa relação causal pode ser encontrada em autores de diferentes perspectivas teórico-metodológicas como Barman (1988), Carvalho (1996), Dolhnikoff (2005) e Gouvêa (2008).
} 
Dado que os parlamentares cultivavam, em maior ou menor grau, vínculos com suas localidades de origem, participando até das esferas de poder ali investidas, estava posto para estes homens que ao fazer política provincial fazia-se, direta ou indiretamente, política nacional e vice-e-versa. Grupos locais se valeram do Parlamento para certificar seus interesses da mesma forma que converteram demandas provinciais em instrumentos de luta e negociação dentro do jogo político da Corte. ${ }^{9}$ Nesse sentido os negócios provinciais foram, a um só tempo, meio e fim da ação política, ajudando a pavimentar o acesso de setores regionais ao interior do Estado. Ficava cada vez mais claro, no entanto, que a convivência num mesmo espaço de poder de propósitos tão distintos era uma faca de dois gumes, sendo talvez melhor operar uma clivagem institucional que conseguisse garanti-los sem que colidissem. Por essa perspectiva as Assembleias Legislativas, oficializadas pelo Ato Adicional, assumem um sentido outro, além da inequívoca ampliação dos poderes provinciais. Elas foram fruto, também, do reconhecimento da existência de demandas específicas de política e do papel institucional que as províncias teriam na estruturação do Estado.

O caso de Minas Gerais permite elucidar que essa inserção dos elementos provinciais na Corte se processou de forma tão cambiante e fragmentada, que polarizações do tipo "interesse local $v s$. interesse nacional" ou "centro vs. província" passam a fazer menos sentido, deixando espaço para uma compreensão mais interligada dessas esferas. Ainda entre os mineiros, e tendo em vista a distribuição de assentos pelo Legislativo, não se pode ocultar o fato de que houvessem políticos mais compromissados com a política provincial do que outros, e que justamente os primeiros fizeram parte, via de regra, da heterogênea oposição ao governo de D. Pedro na Câmara dos deputados. Mas se de um lado o 7 de abril avigorou a interdependência das esferas provincial e nacional, de outro mostrou que a ascensão da Regência não acarretaria, necessariamente, em uma maior contemplação das demandas provinciais, ao menos no que se referia à aprovação das propostas dos Conselhos Gerais. Ao fim e ao cabo, a questão provincial ganhou tamanha proporção que acabou sendo um trunfo e uma fraqueza daqueles que subiriam ao poder após a Abdicação.

\section{Bibliografia}

BARMAN, Roderick. Brazil. The forging of a nation (1798-1852). Stanford: Stanford University Press, 1988.

BITTENCOURT, Vera Lúcia Nagib. De Alteza Real a Imperador: o governo do Príncipe D. Pedro, de abril de 1821 a outubro de 1822. 2007. Tese (Doutorado em História Social) Faculdade de Filosofia, Letras e Ciências Humanas, Universidade de São Paulo, São Paulo, 2007.

\footnotetext{
${ }_{9}$ Movimento semelhante foi constatado por Miriam Dolhnikoff (2005) para o período posterior ao Ato Adicional.
} 
CARVALHO, José Murilo de. A Construção da Ordem. Teatro de Sombras. $2^{\mathrm{a}}$ ed. Rio de Janeiro: Relume Dumará, 1996.

DOLHNIKOFF, Miriam. O pacto imperial: origens do federalismo no Brasil. São Paulo: Globo, 2005.

GOUVÊA, Maria de Fátima Silva. O Império das Províncias. Rio de Janeiro, 1822-1889. Rio de Janeiro: Civilização Brasileira/Faperj, 2008.

LEME, Marisa Saenz. Dinâmicas centrípetas e centrífugas na formação do Estado monárquico no Brasil: o papel do Conselho Geral da Província de São Paulo. Rev. Bras. Hist., São Paulo, v.28, n.55, p.205, jan/jun. 2008.

MANIN, Bernard. Los principios del gobierno representativo. $2^{\mathrm{a}}$ ed. Tradução de Fernando Vallespín. Madrid: Alianza Editorial, 2008.

MOTTA, Rosemary Tofani. Baptista Caetano de Almeida: um mecenas do projeto civilizatório em São João-del-Rei no início do século XIX - a biblioteca, a imprensa e a sociedade literária. Dissertação (Mestrado em História Social), Faculdade de Filosofia e Ciências Humanas, Universidade Federal de Minas Gerais, Belo Horizonte, 2000.

NASCIMENTO, Helvécio Pinto do. Em defesa do "adequado" constitucionalismo: as articulações políticas dos camaristas e padres nas vilas mineiras no contexto separatista (1821-1824). 2010. Tese (Doutorado em História social) - Faculdade de Filosofia e Ciências Humanas da Universidade Federal de Minas Gerais, Belo Horizonte, 2010.

PITKIN, Hanna. The concept of representation. Los Angeles: University of California Press, 1967.

RIBEIRO, Gladys Sabina; PEREIRA, Vantuil. O Primeiro Reinado em revisão. In: GRINBERG, Keila; SALLES, Ricardo (Org.). O Brasil Imperial. Rio de Janeiro: Civilização Brasileira, 2009, v.1: 1808-1831, p.137-174.

SILVA, Ana Rosa Cloclet da. Identidades Políticas e a emergência do novo Estado Nacional: o caso mineiro. In: JANCSÓ, István (Org.). Independência: história e historiografia. São Paulo: Hucitec/FAPESP, 2005, p. 515-555.

SILVA, Wlamir. "Liberais e povo": a construção da hegemonia liberal-moderada na província de Minas Gerais (1830-1834). São Paulo: Hucitec, 2009.

SLEMIAN, Andréa. Sob o império das leis: Constituição e unidade nacional na formação do Brasil (1822-1834). 2006. Tese (Doutorado em História Social) - Faculdade de Filosofia, Letras e Ciências Humanas, Universidade de São Paulo, São Paulo, 2006.

\section{Fontes}

Atas do Conselho de Estado. Direção geral, organização e intr. de José Honório Rodrigues. Brasília, Senado Federal, 1973-1978, 13 v. 
BRASIL, Assembleia Geral do. Anais do Parlamento Brasileiro. Câmara dos Deputados. Rio de Janeiro: Tipografia de Hipólito José Pinho e Cia., 1874-1879.

BRASIL, Assembleia Geral do. Anais do Senado do Império. Rio de Janeiro: Tipografia Nacional, 1914.

BRASIL, Assembleia Geral do. Regimento Interno do Senado. Rio de Janeiro: Imprensa Nacional, 1831.

BRASIL. Constituição Política do Império do Brasil. In: BONAVIDES, Paulo \& AMARAL, Roberto (orgs.). Textos políticos da História do Brasil. Brasília: Senado Federal, 2002, v.1, art.71, capítulo V.

Coleção das decisões do Governo do Império do Brasil de 1829. Rio de Janeiro: Tipografia Nacional, 1877

Coleção dos Diários do Conselho Geral da Província de Minas Gerais. Ouro Preto: Tipografia do Universal, 1831, sessão de 24/12/1831, p.147-148.

Coleção das Leis do Império do Brasil. Rio de Janeiro: Tipografia Nacional, 1876-1878.

O Novo Argos, Ouro Preto, 1 de mar. 1831, 3 jul.1832, 26 jun. 1832.

O Novo Farol Paulistano, São Paulo, 3 dez. 1831.

O Universal, Ouro Preto, 28 set. 1831, 26 out. 1831, 30 abr. 1832, 1 jul. 1833, 3 out. 1834. 